\title{
Crossing coronary arteries
}

\author{
E.S. Zegers, M.W.A. Verkroost, F.W.A. Verheugt
}

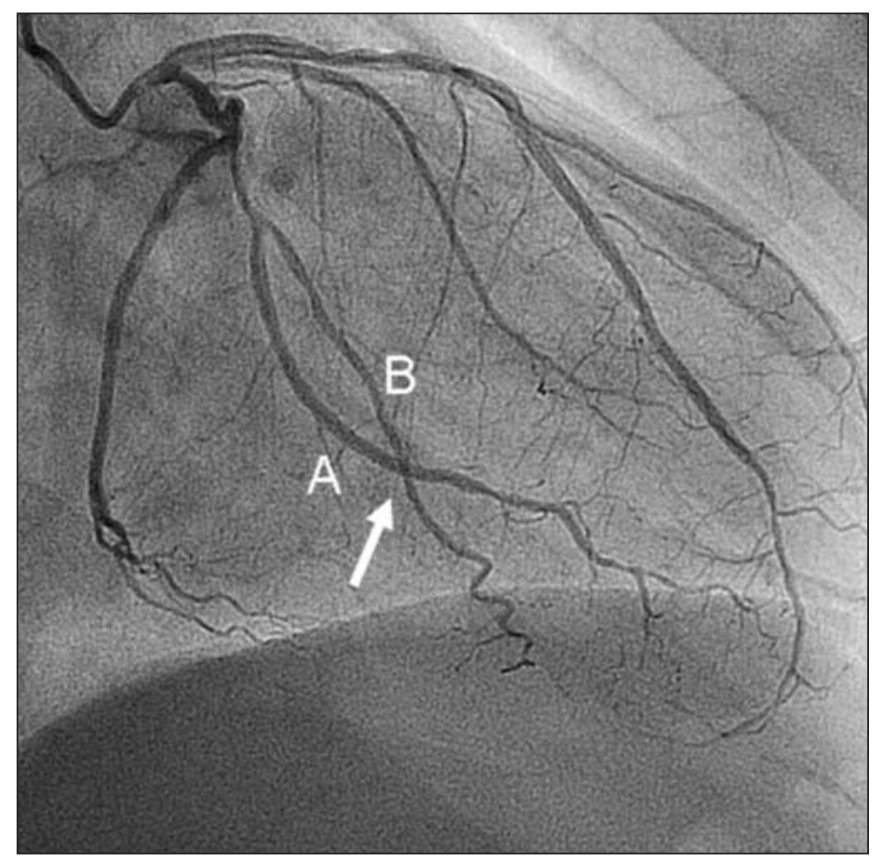

Figure 1. The obtuse marginal arteries $A$ and $B$ continued as two arteries crossing over each other in right antero-oblique (RAO) $-30^{\circ}$ projection (arrow).

73-year-old man was referred to the outpatient Aclinic because of an aortic stenosis and angina pectoris (NYHA class 2). An exercise stress test was abnormal suggesting ischaemia.

\footnotetext{
E.S. Zegers

F.W.A. Verheugt

Department of Cardiology, Heartcentre, Radboud University

Nijmegen Medical Centre, Nijmegen, the Netherlands M.W.A. Verkroost

Department of Thoracic and Cardiac Surgery, Heartcentre, Radboud University Nijmegen Medical Centre, Nijmegen, the Netherlands

Correspondence to: E.S. Zegers

Radboud University Nijmegen Medical Centre, Heartcentre, 670 Cardiology, PO Box 9101, 6500 HB Nijmegen, the Netherlands

E-mail: e.zegers@cardio.umcn.nl
}

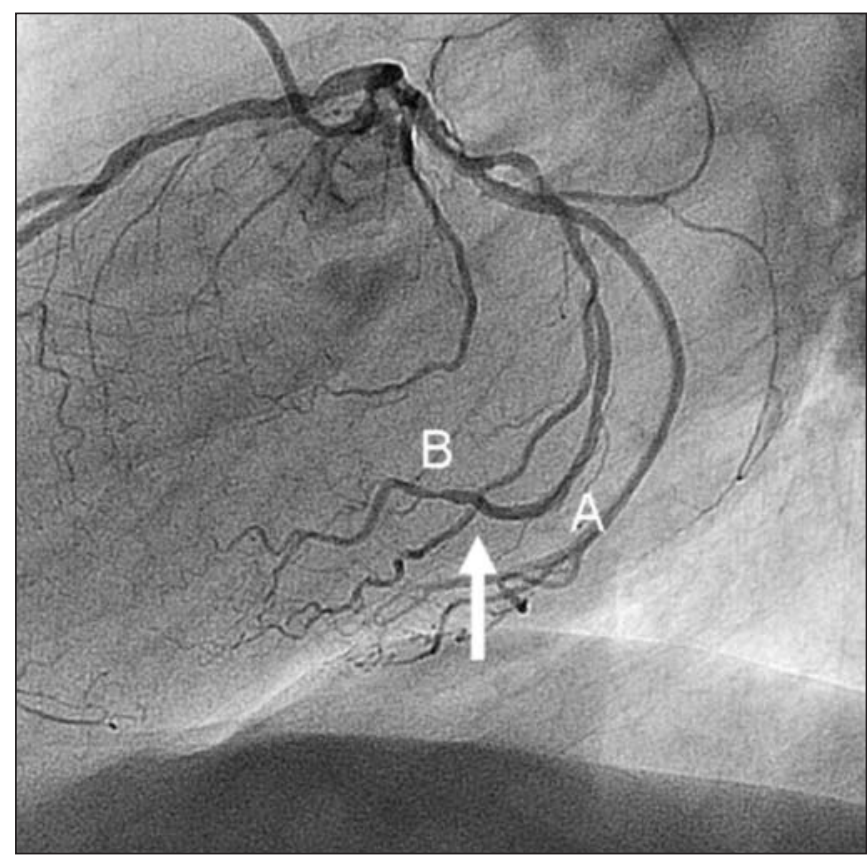

Figure 2. The obtuse marginal arteries $A$ and $B$ continued as two arteries crossing over each other in left antero-oblique (LAO) $90^{\circ}$ projection (arrow).

Coronary angiography revealed significant lesions in the left anterior descending coronary artery and ramus circumflexus. The obtuse marginal artery continued as two arterial branches crossing over each other (figures 1 and 2). There was no angiographic evidence of bridging.

During coronary artery bypass grafting the course of the crossing obtuse marginal arteries was confirmed. The obtuse marginal artery A was crossing over the intramyocardial obtuse marginal artery $\mathrm{B}$ (figures $3 \mathrm{~A}$ and $3 \mathrm{~B}$ ). Myocardial revascularisation of the anterior descending coronary artery with left internal mammary artery was performed. Saphenous vein bypass grafting from the ascending aorta to the obtuse marginal artery was also carried out. An Epic aortic bioprothesis was inserted. No complications occurred. 

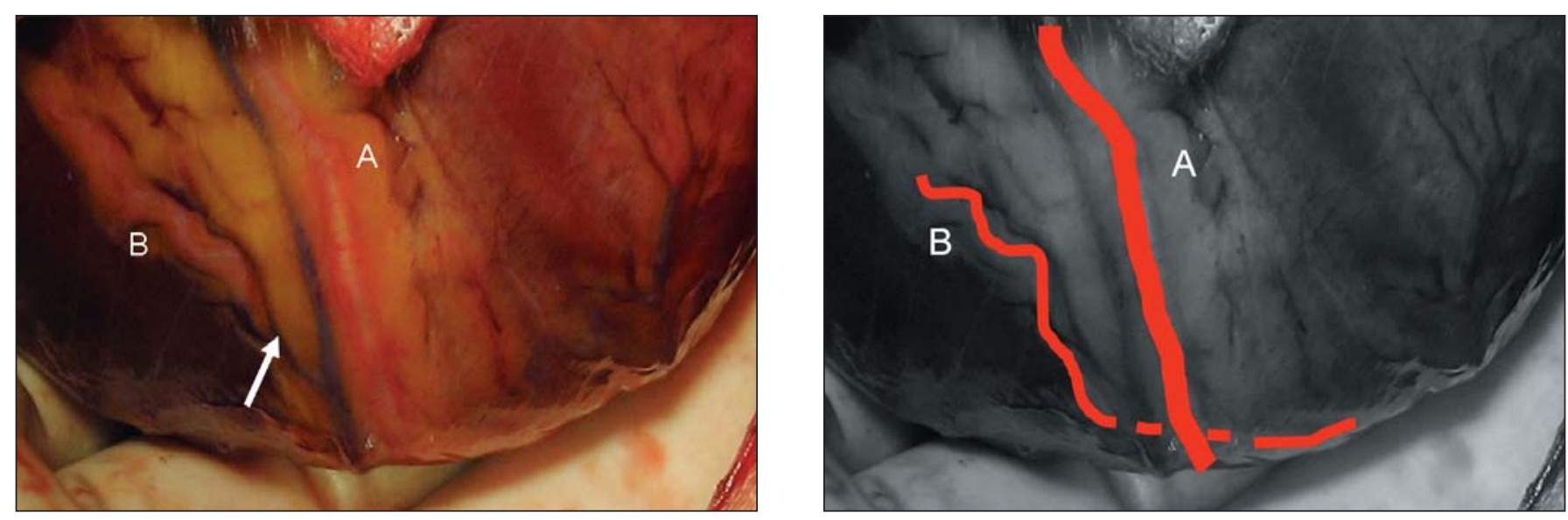

Figure 3. The course of the crossing obtuse marginal arteries was confirmed during coronary artery bypass grafting. The obtuse marginal artery $A$ was crossing over the intramyocardial obtuse marginal artery $B$ (arrow).

It is generally accepted that the major branches of the coronary arteries do not cross, but run parallel to one another. Only a few cases of crossing coronary arteries have been previously published. ${ }^{1-3}$ The incidence has

In this section a remarkable 'image' is presented and a short comment is given.

We invite you to send in images (in triplicate) with a short comment (one page at the most) to Bohn Stafleu van Loghum, PO Box 246, 3990 GA Houten, e-mail: 1.jagers@bsl.nl.

'Moving images' are also welcomed and (after acceptance) will be published as a Web Site Feature and shown on our website: www.cardiologie.nl

This section is edited by M.J.M. Cramer and J.J. Bax. not well been described but seems very low. The coronary artery system presents a great variation with regard to origin, course and branching pattern.

The functional significance of crossing arteries is not known. It is unclear whether this is a coronary artery anomaly or a normal variation of the coronary anatomy.

\section{References}

1 Muyldermans LL, van den Heuvel PA, Ernst SM. Epicardial crossing of coronary arteries: a variation of coronary arterial anatomy. Int J Cardiol 1985;7:416-9.

2 Bilazarian SD, Jacobs AK, Fonger JD, et al. Case report of a coronary anomaly: crossing obtuse marginal arteries. Cathet Cardiovasc Diagn 1991;23:130-2.

3 Yilmaz H, Demir I. Crossing epicardial coronary arteries. Heart 2005;91:1523. 